\title{
Severe warm autoimmune hemolytic anemia in COVID-19 managed with least incompatible RBC product and glucocorticoids
}

\author{
Tien-Chan Hsieh ${ }^{1,2}$ (1) O Oleg Sostin ${ }^{1}$
}

Received: 28 January 2021 / Accepted: 7 February 2021 / Published online: 18 February 2021

(C) The Author(s), under exclusive licence to Springer-Verlag GmbH, DE part of Springer Nature 2021

Dear Editor,

Warm autoimmune hemolytic anemia (AIHA) is a rare autoimmune disorder mediated by autoantibodies that are active at normal body temperature. It is commonly associated with underlying conditions, such as viral infections, autoimmune disorders, lymphoproliferative diseases [1]. Recently, a few case reports found association between warm AIHA and COVID-19 [2-4]. Here we present a case of a new onset warm AIHA in a COVID-19 patient.

An 84-year-old Caucasian man with a past medical history of hypercholesterinemia who developed dry cough, mild shortness of breath, and fever 13 days prior to the presentation. Three days after onset, he was tested positive for SARS-CoV2. The patient was hypoxic upon arrival to the hospital, requiring $4 \mathrm{~L} / \mathrm{min}$ of supplemental oxygen. Physical exam revealed scleral icterus. Laboratory work was significant for severe anemia (hemoglobin $4.4 \mathrm{~g} / \mathrm{dL}$ ) and indirect bilirubinemia $(2.3 \mathrm{mg} / \mathrm{dL})$. Further analysis showed lactate dehydrogenase of $1253 \mathrm{U} / \mathrm{L}$, haptoglobin $<10 \mathrm{mg} / \mathrm{dL}$, and reticulocyte count of $120 \times 10^{9} / \mathrm{L}$. Peripheral smear identified numerous nucleated RBCs and microspherocytes. CT scan of the chest, abdomen, and pelvis did not show any occult hemorrhage but revealed diffuse patchy bilateral groundglass opacities within the lungs. The patient was found to have positive direct Coombs test with anti-K antibodies and IgG pan-agglutinins. He received packed RBCs that were type-specific, K-negative, and "least incompatible" based on cross-match. The

Tien-Chan Hsieh

Tien-Chan.Hsieh@nuvancehealth.org

1 Department of Medicine, Danbury Hospital, 24 Hospital Ave, Danbury, CT 06810, USA

2 Department of Medicine, The University of Vermont, 89 Beaumont Ave, Burlington, VT 05405, USA diagnosis of warm AIHA secondary to COVID-19 was made. Convalescent plasma therapy, remdesivir, and dexamethasone were initiated. In the first $24 \mathrm{~h}$, he received 5 units of packed RBCs and remained stable, with hypoxia and dyspnea improving significantly on the second day. He was discharged with prednisone taper dose. His hemoglobin has been stable for 12 weeks since discharge.

Recognizing warm AIHA in COVID-19 is important to avoid delay in treatment. To our best knowledge, there have been 20 AIHA cases reported in COVID-19. Warm AIHA was found in only seven cases (Table 1) [2-6]. The mean age is 63.3 years old. On average, it takes 8 days from the first COVID-19 symptom to the development of warm AIHA. Anemia-related symptoms are common. Physical exam may show jaundice. The mean hemoglobin is 5.7. In addition to low hemoglobin, laboratory evaluation may be notable for increased reticulocyte count, elevated lactate dehydrogenase, low haptoglobin, indirect bilirubinemia, and spherocytosis/ microspherocytosis. Diagnosis is made based on the presence of hemolytic anemia mediated by warm antibodies. Due to the presence of pan-reacting autoantibodies, identifying crossmatched blood products may not be possible. If severe anemia is present, clinicians should contact blood bank immediately for type-specific, "least incompatible" blood products. Warm AIHA is often treated with glucocorticoids in addition to transfusion. Rituximab can be considered based on the severity of the anemia and response to the steroid therapy [1]. Since glucocorticoids are also used in moderate to severe COVID19 cases, it is reasonable to treat COVID-19-associated warm AIHA with glucocorticoids [7].

In summary, warm AIHA is a rare but severe complication of COVID-19. Recognizing the necessity to initiate transfusion with "least incompatible" blood products is curial. Glucocorticoids can be used to treat COVID-19 patients with warm AIHA. 
Table 1 Summary of the COVID-19-associated warm AIHA in the literature. $H T N$ hypertension, $C K D$ chronic kidney disease, $C L L$ chronic lymphocytic leukemia, MGUS monoclonal gammopathy of undetermined significance, $H L D$ hyperlipidemia, $D M$ diabetes mellitus, $C M$ cardiomyopathy, COPD chronic obstructive pulmonary disease, ITP idiopathic thrombocytopenic purpura, $C$ complement, ? insufficient data

Age Gender Comorbidity

$\mathrm{Hgb} \quad \mathrm{LDH}$ Haptoglobin $(\mathrm{g} / \mathrm{dL}) \quad(\mathrm{U} / \mathrm{L}) \quad(\mathrm{g} / \mathrm{L})$ class
Treatment Response temperature between

the onset of COVID-19 and AIHA

\begin{tabular}{|c|c|c|c|c|c|c|c|c|c|c|c|}
\hline $\begin{array}{l}\text { Hindilerden et al. } \\
\text { [2] }\end{array}$ & 56 & M & HTN & 4.3 & 2529 & 11.5 & $\mathrm{IgG}, \mathrm{C} 3 \mathrm{~d}$ & Warm & 4 & $\begin{array}{l}\text { Steroids, } \\
\text { IVIG }\end{array}$ & Improving \\
\hline \multirow[t]{4}{*}{$\begin{array}{l}\text { Lazarian } \\
\quad \text { et al. [3] }\end{array}$} & 61 & M & $\begin{array}{l}\text { HTN, CKD, } \\
\text { CLL }\end{array}$ & 6 & 1000 & $<10$ & $\mathrm{IgG}, \mathrm{C} 3 \mathrm{~d}$ & Warm & 13 & Steroids & Unknown \\
\hline & 89 & $\mathrm{~F}$ & $\begin{array}{l}\text { HTN, CKD, } \\
\text { MGUS }\end{array}$ & 8.4 & 598 & $<10$ & $\mathrm{IgG}, \mathrm{C} 3 \mathrm{~d}$ & Warm & 7 & Steroids & Unknown \\
\hline & 75 & M & $\begin{array}{l}\text { DM, HLD, } \\
\text { CM, } \\
\text { COPD, CLL }\end{array}$ & 7.1 & 2000 & $<10$ & $\operatorname{IgG}$ & Warm & 6 & $\begin{array}{l}\text { Transfusion } \\
\text { only }\end{array}$ & Unknown \\
\hline & 61 & M & $\mathrm{DM}$ & 7 & 1800 & $<10$ & IgG & Warm & 9 & $\begin{array}{l}\text { Steroids, } \\
\quad \text { Rituximab }\end{array}$ & Unknown \\
\hline $\begin{array}{l}\text { Wahlster } \\
\text { et al. [4] }\end{array}$ & 17 & M & ITP & 2.5 & 1280 & $?$ & $\mathrm{IgG}, \mathrm{C} 3$ & Warm & 4 & Steroids & Improving \\
\hline Our case & 84 & M & HLD & 4.4 & 1253 & $<10$ & $\begin{array}{l}\mathrm{IgG}, \\
\quad \text { anti-K }\end{array}$ & Warm & 13 & Steroids & Improving \\
\hline
\end{tabular}

Availability of data and material The data that support the findings of this study are available on request from the corresponding author, TienChan Hsieh.

Code availability (software application or custom code) Not applicable

Authors' contributions Tien-Chan Hsieh conceived the presented idea and drafted the manuscript. Both authors contributed to the final manuscript.

\section{Declarations}

Conflict of interest None to declare

Ethics approval Not required

Consent to participate Not required

Consent for publication Not required

\section{References}

1. Brodsky RA (2019) Warm Autoimmune Hemolytic Anemia. N Engl J Med 381(7):647-654. https://doi.org/10.1056/NEJMcp1900554

2. Hindilerden F, Yonal-Hindilerden I, Akar E, Yesilbag Z, Kart-Yasar K (2020) Severe Autoimmune Hemolytic Anemia in COVID-19
Infection, Safely Treated with Steroids. Mediterr J Hematol Infect Dis 12(1):e2020053. https://doi.org/10.4084/MJHID.2020.053

3. Lazarian G, Quinquenel A, Bellal M, Siavellis J, Jacquy C, Re D, Merabet F, Mekinian A, Braun T, Damaj G, Delmer A, Cymbalista F (2020) Autoimmune haemolytic anaemia associated with COVID19 infection. Br J Haematol 190(1):29-31. https://doi.org/10.1111/ bjh.16794

4. Wahlster L, Weichert-Leahey N, Trissal M, Grace RF, Sankaran VG (2020) COVID-19 presenting with autoimmune hemolytic anemia in the setting of underlying immune dysregulation. Pediatr Blood Cancer 67:e28382. https://doi.org/10.1002/pbc.28382

5. Huscenot T, Galland J, Ouvrat M, Rossignol M, Mouly S, Sene D, Group ALC (2020) SARS-CoV-2-associated cold agglutinin disease: a report of two cases. Ann Hematol 99(8):1943-1944. https:// doi.org/10.1007/s00277-020-04129-9

6. Jacobs J, Eichbaum Q (2020) COVID-19 associated with severe autoimmune hemolytic anemia. Transfusion. 61:635-640. https:// doi.org/10.1111/trf.16226

7. Lamontagne F, Agoritsas T, Macdonald H, Leo YS, Diaz J, Agarwal A, Appiah JA, Arabi Y, Blumberg L, Calfee CS, Cao B, Cecconi M, Cooke G, Dunning J, Geduld H, Gee P, Manai H, Hui DS, Kanda S, Kawano-Dourado L, Kim YJ, Kissoon N, Kwizera A, Laake JH, Machado FR, Qadir N, Sarin R, Shen Y, Zeng L, BrignardelloPetersen R, Lytvyn L, Siemieniuk R, Zeraatkar D, Bartoszko J, Ge L, Maguire B, Rochwerg B, Guyatt G, Vandvik PO (2020) A living WHO guideline on drugs for covid-19. BMJ 370:m3379. https://doi. org/10.1136/bmj.m3379

Publisher's note Springer Nature remains neutral with regard to jurisdictional claims in published maps and institutional affiliations. 